\title{
Hemolytic anemia and a new murmur in a 77-year-old man
}

\author{
Danyal Ladha MD, Karima Khamisa MD, Steven Promislow MD
}

Cite as: CMAJ 2021 September 7;193:E1389. doi: 10.1503/cmaj.202620

A

77-year-old man with vascular dementia presented to the emergency department with dyspnea. His medical history included rheumatic mitral stenosis with mechanical mitral valve replacement in 2001. On examination, he was afebrile, jaundiced and euvolemic. On auscultation we heard a new holosystolic murmur, loudest at the apex. Laboratory investigations revealed low hemoglobin of 89 (normal 125170) g/L, mean corpuscular volume 98.9 (normal 80-100) fL, a normal platelet count, undetectable haptoglobin level, and elevated lactate dehydrogenase (1603 [normal 99-167] U/L), bilirubin (total 45 [normal < 15] $\mu \mathrm{mol} / \mathrm{L}$; direct 19 [normal < 5] $\mu \mathrm{mol} / \mathrm{L}$ ) and reticulocyte counts (42.9\%, normal 1.5\%-15\%). A direct antiglobulin test (DAT [Coombs test]) was negative. We saw numerous schistocytes on peripheral blood smear (Figure 1). A transthoracic echocardiogram showed dehiscence of the prosthetic mitral valve posteriorly, with substantial paravalvular mitral regurgitation not present on echocardiogram 5 months earlier (Appendix 1, available at www.cmaj.ca/lookup/ doi/10.1503/cmaj.202620/tab-related-content). The patient's left ventricular ejection fraction was 50\%-55\%. Negative blood cultures, coupled with the absence of fever or other infectious findings, made endocarditis unlikely. The patient was given a diagnosis of macroangiopathic hemolytic anemia secondary to prosthetic valve dehiscence. He was managed conservatively, owing to his poor baseline functional status.

Valve-associated hemolytic anemia has been reported in as many as $1 \%$ of patients with prosthetic valves. ${ }^{1}$ The pathophysiology involves paravalvular regurgitation causing mechanical trauma to red blood cells. Clinical features include jaundice and a new murmur. The blood smear typically indicates numerous schistocytes and a normal platelet count. Other laboratory findings include an elevated lactate dehydrogenase, bilirubin and reticulocyte count with low haptoglobin. In patients with a prosthetic valve who present with anemia, it is important to consider valve-associated hemolysis in the differential diagnosis. Initial workup should include a blood smear, DAT and transthoracic echocardiography to assess prosthetic valve function. If evidence of paravalvular regurgitation exists, definitive management is either percutaneous paravalvular leak closure or surgical repair. Medical and supportive measures (transfusions, folic acid supplementation) may be helpful in the short term. ${ }^{2}$

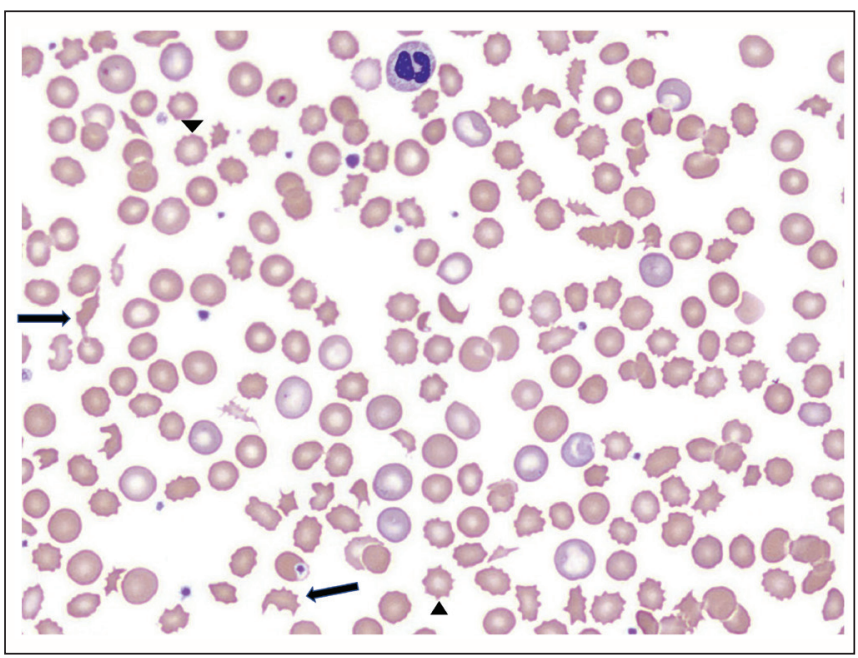

Figure 1: Peripheral blood smear of a 77-year-old patient with a mechanical mitral valve who presented with hemolytic anemia. The smear shows numerous schistocytes (arrows), acanthocytes (arrowheads), and a normal platelet count.

\section{References}

1. Alkhouli M, Farooq A, Go RS, et al. Cardiac prostheses-related hemolytic anemia. Clin Cardiol 2019;42:692-700.

2. Eleid MF, Cabalka AK, Malouf JF, et al. Techniques and outcomes for the treatment of paravalvular leak. Circ Cardiovasc Interv 2015;8:e001945. doi: 10.1161/ CIRCINTERVENTIONS.115.001945.

\section{Competing interests: None declared.}

This article has been peer reviewed.

The authors have obtained consent from the patient's family.

Affiliations: Department of Medicine (Ladha, Khamisa), Ottawa Hospital Department of Medicine at the University of Ottawa, Ont.; Section of Cardiology (Promislow), University of Manitoba, Winnipeg, Man.

Content licence: This is an Open Access article distributed in accordance with the terms of the Creative Commons Attribution (CC BY-NCND 4.0) licence, which permits use, distribution and reproduction in any medium, provided that the original publication is properly cited, the use is noncommercial (i.e., research or educational use), and no modifications or adaptations are made. See: https://creativecommons.org/ licenses/by-nc-nd/4.0/

Correspondence to: Danyal Ladha, dladha@toh.ca 